\title{
Experience with a Simplified, Standardized 4-Hour Gastric-Emptying Protocol
}

\author{
Harvey A. Ziessman ${ }^{1}$, Dacian V. Bonta ${ }^{1}$, Sibyll Goetze ${ }^{1}$, and William J. Ravich ${ }^{2}$ \\ ${ }^{1}$ Division of Nuclear Medicine, Russell H. Morgan Department of Radiology and Radiological Sciences, Johns Hopkins Medical \\ Institutions, Baltimore, Maryland; and ${ }^{2}$ Division of Gastroenterology, Department of Medicine, Johns Hopkins Medical Institutions, \\ Baltimore, Maryland
}

Gastric-emptying studies have no accepted standard methodology or reference values. A simplified standardized protocol with a large reference database has been proposed, with imaging obtained at only $0,1,2$, and $4 \mathrm{~h}$. The rationale for its 4 -h length is data suggesting that delayed emptying is detected with higher sensitivity at $4 \mathrm{~h}$ than at $2 \mathrm{~h}$. The purpose of the current investigation was to review our 2-y experience using this protocol, to determine the added value of 4-h imaging, and to determine whether the lag phase can predict delayed emptying. Methods: After ingesting a sandwich made with ${ }^{99 m}$ Tc-sulfur colloid egg substitute, 175 patients were imaged immediately, every 10 min for $1 \mathrm{~h}$, and then at 2, 3, and $4 \mathrm{~h}$. Percentage retention was calculated for each interval. Sensitivities, specificities, predictive values, and receiver operating characteristic $(\mathrm{ROC})$ curves were computed for the 1-, 2-, and 3-h intervals on the basis of normal 4-h values. Data were analyzed to determine the added value of the 4-h study. Thresholds were sought that optimized accuracy. $\mathrm{ROC}$ analysis was used to determine the predictive value of the lag phase. Results: Gastric emptying was delayed in $20 \%$ of patients at $2 \mathrm{~h}$ and in $26 \%$ at $4 \mathrm{~h}$, a $29 \%$ increase in abnormal studies $(P<0.02)$. Of those normal at $2 \mathrm{~h}, 13 \%$ became abnormal at 4 $\mathrm{h}$. Of those with delayed emptying at $2 \mathrm{~h}, 24 \%$ normalized at $4 \mathrm{~h}$. Compared with the study at $4 \mathrm{~h}$, the study at $2 \mathrm{~h}$ had a $59 \%$ sensitivity, 94\% specificity, 76\% PPV, and $87 \%$ NPV. ROC analysis showed that the areas under the ROC curve (AUC) were 0.75 , 0.93 , and 0.97 at 1,2 , and $3 \mathrm{~h}$, respectively. The threshold for optimal accuracy for 3-h data was estimated to be greater than $30 \%$ retention. The accuracy of this threshold was $91 \%$. The lag phase AUC for predicting delayed emptying at $4 \mathrm{~h}$ was 0.60. Conclusion: This first investigation of a large referral patient population using a standardized protocol found that abnormal emptying is detected with greater sensitivity at $4 \mathrm{~h}$ than at $2 \mathrm{~h}$ and that the lag phase is not predictive of delayed emptying.

Key Words: gastric emptying; lag phase; stomach; gastroparesis; standardization

J Nucl Med 2007; 48:568-572

DOI: 10.2967/jnumed.106.036616

Received Sep. 21, 2006; revision accepted Jan. 10, 2007.

For correspondence or reprints contact: Harvey A. Ziessman, MD, Johns Hopkins Outpatient Center, 601 N. Caroline St., Suite 3231, Baltimore, MD 21278.

E-mail: hziessm1@jhmi.edu

COPYRIGHT $\odot 2007$ by the Society of Nuclear Medicine, Inc.
$\mathbf{T}$ he radionuclide gastric-emptying study has long been the standard method for measuring gastric motility. However, clinicians increasingly express concern about the lack of standardized methodology across institutions and imaging centers. The meal, study length, acquisition, processing methods, quantification, and reference values differ.

A simplified and standardized protocol that has support in the gastroenterology community has been proposed by Tougas et al. (1). In that publication, reference gastric-emptying data were analyzed in 123 healthy subjects from multiple institutions in Europe, Canada, and the United States. The methodology is simplified in the sense that imaging is performed at only 4 intervals $-0,1,2$, and $4 \mathrm{~h}$-after ingestion of a low-fat meal. Their data suggested that these limited imaging times provided results similar to those of more frequent image acquisition. The rationale for the 4-h study length is 2 other reports indicating that delayed gastric emptying is detected with higher sensitivity at $4 \mathrm{~h}$ than at $2 \mathrm{~h}(2,3)$.

We have been using a modification of this protocol since May 2004. The purpose of this investigation was to review our experience with this simplified, standardized protocol in a large population of referred patients. We sought to determine whether delayed gastric empting was detected with increased sensitivity at $4 \mathrm{~h}$ than at $2 \mathrm{~h}$ using this protocol. By modifying the protocol, we also sought to determine whether a delay in the lag phase might be predictive of delayed gastric emptying.

\section{MATERIALS AND METHODS}

Between May 1994 and March 2005, 225 consecutive adult gastric-emptying studies were performed at our institution; the patients who underwent these studies served as the study population. Patients were excluded from analysis if they did not ingest the entire meal within $15 \mathrm{~min}$, had a history of abnormal gastric or esophageal anatomy, had undergone prior surgery, were receiving gastric prokinetic drugs, or had evidence of esophageal reflux or esophageal retention on scintigraphic imaging. The reason for exclusion was the concern that the reference values might not apply to these patients-for example, those who consumed only a portion of the whole meal-and that the results would potentially be erroneous because of difficulties in calculating accurate results-for example, in those patients with reflux or esophageal 
retention. Thus, 175 patients (124 of whom were female and 51 male) met the criteria and served as the basis for our review. Patients ranged in age from 17 to $88 \mathrm{y}$ (mean \pm SD, $48.4 \pm 15.1 \mathrm{y}$ ). The population represented the broad spectrum of patients usually referred for gastric-emptying studies, that is, those with a variety of dyspeptic symptoms including postprandial nausea, vomiting, abdominal pain, and gastroesophageal reflux. Eighteen had insulindependent diabetes and had similar symptoms or poor diabetic control.

The patients fasted overnight before the study. The radiolabeled meal consisted of $120 \mathrm{~g}$ of egg substitute, equivalent to 2 large eggs (Classic Optimum Choice liquid egg product; SYSCO Corp.); toasted white bread (2 slices); strawberry jam (two 14-g packages; The J.M. Smucker Co.); and water (120 mL). The meal had $1,067 \mathrm{~kJ}(255 \mathrm{kcal})$ and included $75 \%$ carbohydrates, $24 \%$ protein, $2 \%$ fat, and $2 \%$ fiber (1). ${ }^{99 \mathrm{~m}} \mathrm{Tc}$-sulfur colloid (37 MBq) was mixed with the egg substitute and cooked for $2 \mathrm{~min}$ in a microwave oven.

The protocol of Tougas et al. requires imaging at $0,1,2$, and $4 \mathrm{~h}$ after meal ingestion (1). The patients in this investigation were also imaged every $10 \mathrm{~min}$ during the first hour and additionally at $3 \mathrm{~h}$. The patients were asked to sit in the waiting room between imaging sessions. Simultaneous anterior and posterior 1-min images $(128 \times 128$ matrix $)$ were obtained with the patient supine using a dual-head $\gamma$-camera with a low-energy high-resolution parallel-hole collimator. A $20 \%$ window was centered on $140 \mathrm{keV}$. A gastric region of interest was drawn using computer software for each image set. The geometric mean of the anterior and posterior views was determined, and the percentage retention was calculated for each interval. The values for abnormal retention from the Tougas protocol (median and 95th percentile) were used: Delayed gastric retention was defined as a delay of greater than $90 \%$ at $1 \mathrm{~h}, 60 \%$ at $2 \mathrm{~h}$, and $10 \%$ at $4 \mathrm{~h}(1)$.

For analysis, data were recorded as integers (1-100) representing the percentage activity retained in the stomach at various times. The number of patients with a percentage retained activity less than or equal to the thresholds used by Tougas et al. for the time points was labeled "normal" with regard to that criterion (1).

To test the statistical significance of greater abnormal emptying at $4 \mathrm{~h}$ than at $2 \mathrm{~h}$, we performed a simple bootstrap experiment (4). The resampling procedure creates alternative samples from the original dataset by drawing with replacement. The statistical significance was determined ( $P$ value).

By varying the threshold between normal and abnormal patient studies, we constructed receiver operating characteristic (ROC) curves for detection of delayed emptying based on the percentage retained activity at 1,2 , and $3 \mathrm{~h}$. The standard for truth was considered emptying of $90 \%$ or more at $4 \mathrm{~h}(1)$. New thresholds that optimized accuracy (number of patients correctly classified divided by total patients) in our dataset were determined.

ROC curves were analyzed to evaluate the utility of the lag phase in predicting delayed emptying. The lag phase was determined by 2 methods: a 5\% drop in counts from peak counts and the first appearance of bowel activity (5).

\section{RESULTS}

Of the 175 patients included in the analysis, no data were available for 3 patients at $1 \mathrm{~h}$ and for 1 patient at $2 \mathrm{~h}$. At $1 \mathrm{~h}$ after ingestion of the meal, $154(90 \%)$ of 172 patients had normal gastric emptying and $18(11 \%)$ had delayed gastric emptying according to the Tougas data (1). At $2 \mathrm{~h}, 140$ $(81 \%)$ of 174 patients had normal emptying and 34 patients (20\%) had delayed gastric emptying. At $4 \mathrm{~h}, 130(74 \%)$ of 175 patients had normal emptying and 45 patients $(26 \%)$ had delayed emptying. This was a $29 \%(10 / 34)$ increase in the number of abnormal studies. One of the 45 abnormal studies at $4 \mathrm{~h}$ was not observed at $2 \mathrm{~h}$ (Table 1).

Of the 154 normal studies at $1 \mathrm{~h}, 31(20 \%)$ became abnormal at $4 \mathrm{~h}$. Of the 140 normal studies at $2 \mathrm{~h}, 18(13 \%)$ became abnormal at $4 \mathrm{~h}$. On the other hand, of the 18 abnormal studies at $1 \mathrm{~h}, 4(22 \%, 9 \%-55 \%$ confidence interval) became normal at $4 \mathrm{~h}$. Of the 34 abnormal studies at $2 \mathrm{~h}, 8$ (24\%, 4\%-47\% confidence interval) became normal at $4 \mathrm{~h}$ (Table 1).

Using 500 bootstrap samples (4), we found that 9 samples contained more patients that crossed from abnormal to normal than patients that crossed from normal to abnormal. Therefore, the statistical hypothesis that more studies are abnormal at $4 \mathrm{~h}$ than at $2 \mathrm{~h}$ is significant, at a $P$ value of 0.018 .

Apparent rapid emptying was estimated on the basis of the percentage retention at 1 and $2 \mathrm{~h}$ using different cutoffs $(<30 \%,<20 \%$, and $<10 \%)$ (Table 2$)$.

The sensitivity, specificity, positive predictive value, and negative predictive value for 1 and $2 \mathrm{~h}$ relative to the 4-h values of Tougas et al. are summarized in Table 3 .

The areas under the ROC curve (AUC) for each interval, compared with the 4-h normal values, were 0.75 at $1 \mathrm{~h}, 0.93$ at $2 \mathrm{~h}$, and 0.97 at $3 \mathrm{~h}$ (Fig. 1).

The threshold values that optimized accuracy at 1,2, and $3 \mathrm{~h}$ and their associated sensitivity, specificity, accuracy, and predictive values are shown in Table 4.

On ROC analysis, the AUC for the lag phase in predicting delayed gastric emptying was 0.60 for a $5 \%$ drop in counts from peak counts and 0.53 using the first appearance of bowel activity (FABA) (Fig. 2).

\section{DISCUSSION}

The first report using radionuclide gastric-emptying methodology was published in 1966 , describing the use of ${ }^{51} \mathrm{Cr}$ to measure emptying (6). Since that time, many different radiopharmaceuticals and methodologies have been used. Although various nonradionuclide methods have been

TABLE 1

Normal and Abnormal Gastric Emptying at 1, 2, and 4 Hours

\begin{tabular}{lccccc}
\hline & \multicolumn{2}{c}{ Normal $(n)$} & & \multicolumn{2}{c}{ Abnormal $(n)$} \\
\cline { 2 - 3 } \cline { 5 - 6 } Timing & Total & Crossovers* & & Total & Crossovers $^{\dagger}$ \\
\hline $1 \mathrm{~h}$ & 154 & $31(14 \%-26 \%)$ & & 18 & $4(9 \%-55 \%)$ \\
$2 \mathrm{~h}$ & 140 & $18(8 \%-19 \%)$ & & 34 & $8(4 \%-47 \%)$ \\
$4 \mathrm{~h}$ & 130 & & & 45 &
\end{tabular}

*Patients normal at 1 or $2 \mathrm{~h}$ who became abnormal at $4 \mathrm{~h}$.

${ }^{\dagger}$ Patients abnormal at 1 and $2 \mathrm{~h}$ who became normal at $4 \mathrm{~h}$. Data in parentheses are $95 \%$ confidence intervals. 
TABLE 2

Number and Percentage of Patients with Apparent Rapid Gastric Emptying

\begin{tabular}{lccc}
\hline \multirow{3}{*}{ Timing } & \multicolumn{3}{c}{ Percentage reduction } \\
\cline { 2 - 4 } & $<30 \%$ & $<20 \%$ & $<10 \%$ \\
\hline $1 \mathrm{~h}$ & $5 / 172(2.9 \%)$ & $3 / 172(1.7 \%)$ & $0 / 172(0 \%)$ \\
$2 \mathrm{~h}$ & $21 / 174(12.6 \%)$ & $20 / 174(11.5 \%)$ & $19 / 174(10.9 \%)$ \\
\hline
\end{tabular}

described, the radionuclide methodology has stood the test of time and is the accepted standard for measuring gastric motility.

There are numerous reasons why different protocols and reference values are in clinical use today. Advances in camera technology, such as the availability of dual-head cameras, have led to changes in methodology. Our increased understanding of gastric physiology has been an impetus for protocol changes; for example, a frequent framing rate allows for more accurate measurement of the lag phase and rate of emptying $(5,7)$. Commercial software that permits routine attenuation correction has become widely available. Quantification is often calculated as a half-time of emptying or percentage emptying at the study end, although some have advocated more sophisticated analyses such as modified power exponential, antral motility, and gastric accommodation $(8-10)$. Reference values depend on the methodology used, especially the meal content, but also on the acquisition, processing, and quantification methods $(11,12)$. Thus, the reference values used should be validated and based on the specific methodology used. Today, the specific protocol that is used in an imaging center is determined by multiple factors, such as the instrumentation and software available and the interest, knowledge, and preference of the imaging physician.

Referring physicians are increasingly frustrated by the different methodologies used. The referring clinician attempts to understand the patient's gastric-emptying results in light of published literature and presentations at medical meetings. However, the methodology and reference values vary widely, even between the hospitals to which an individual physician refers patients. Furthermore, multiinstitutional clinical trials are difficult to establish because of the lack of a general standardized protocol.
Standardized approaches to gastric emptying have been advocated (13), but there is no general agreement on a standard protocol. In 2000, Tougas, et al. published a multicenter study on 123 healthy subjects from institutions in Europe and North America and established values for delayed gastric emptying (1). The authors and many gastroenterologists promote the protocol as simplified and cost-effective because it requires imaging at only 4 times after ingestion of the meal- $0,1,2$, and $4 \mathrm{~h}$ - and can easily be duplicated at any imaging center. Quantification requires calculation of only the percentage gastric retention at these intervals.

In 1991, from a study of 14 patients and 37 healthy subjects, it was reported that a limited number of data points, at 0,2 , and $4 \mathrm{~h}$, provided an approximate and adequate representation of gastric emptying when compared with more frequent image acquisition (14). The same investigator group subsequently published a study on 35 patients using the simplified protocol and reported that more patients with delayed gastric emptying were detected at $4 \mathrm{~h}$ than at $2 \mathrm{~h} \mathrm{(3).}$ In 2001, a different group reported on 129 patients who were studied using a different simplified protocol. Delayed emptying was detected in $33 \%$ of patients at $2 \mathrm{~h}$ and in $42 \%$ at $4 \mathrm{~h}$ (2). However, neither study reported a statistically significant difference.

In our investigation of 175 patients using the Tougas protocol, we also found more patients with delayed emptying at $4 \mathrm{~h}$ than at $2 \mathrm{~h}(26 \%$ vs. $20 \%)$. This was a $29 \%$ increase in the number of abnormal studies and was statistically significant $(P<0.02)$. We also found that some patients with delayed emptying at $2 \mathrm{~h}$ had normal emptying at $4 \mathrm{~h}$ (Table 1). Similar findings have been previously reported (2).

One limitation of the Tougas protocol is the lack of published 3-h data (1). In a prior study in which 3-h imaging was performed, the 3 -h time point was at least as sensitive as the 4-h time point for detection of abnormal emptying (2). In our protocol, patients were also imaged at $3 \mathrm{~h}$. Our ROC analysis, using the Tougas 4-h data as the standard, found an AUC of $97 \%$ for the 3-h emptying values (Fig. 1), suggesting a good correlation between the test results at 3 and $4 \mathrm{~h}$. Our analysis also suggested that an optimal threshold for 3-h emptying would be greater than $30 \%$ retention (Table 4 ). The accuracy of this threshold in our patient dataset was $91 \%$ (Table 4), with $9 \%$ of the patients having discordant results

TABLE 3

Sensitivity, Specificity, and Predictive Values of Abnormal Emptying at 1 and 2 Hours Compared with 4 Hours

\begin{tabular}{lcccr}
\hline Gastric retention & Sensitivity & Specificity & Positive predictive value & Negative predictive value \\
\hline$>90 \%$ at $1 \mathrm{~h}$ & $31 \%(14 / 45)$ & $97 \%(123 / 127)$ & $78 \%(14 / 18)$ & $80 \%(123 / 154)$ \\
$>60 \%$ at $2 \mathrm{~h}$ & $59 \%(26 / 44)$ & $94 \%(122 / 130)$ & $76 \%(26 / 34)$ & $87 \%(122 / 140)$
\end{tabular}

The standard for a 4-h abnormal value was a retention of greater than $10 \%$ (Tougas et al. (1)). The data in parentheses were used for the calculation. The numerator is the number of patients correctly assigned by the intermediate time criterion to the same category as the 4-h criterion (e.g., abnormal emptying), and the denominator is the total number of patients from that category evaluated at the given time. One true-positive was not evaluated at $2 \mathrm{~h}$, and 3 true-negatives were not evaluated at $1 \mathrm{~h}$; hence, only 44 of the 45 patients with abnormal emptying at $4 \mathrm{~h}$ were evaluated at $2 \mathrm{~h}$, and only 127 of 130 patients with normal emptying at $4 \mathrm{~h}$ were evaluated at $3 \mathrm{~h}$. 


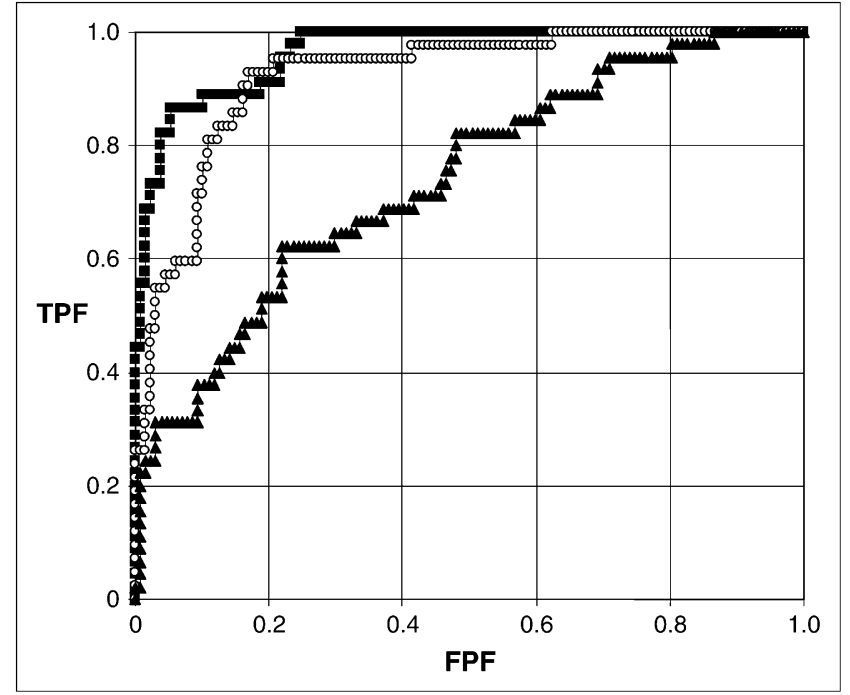

FIGURE 1. ROC curves for 1-h $(\boldsymbol{\Delta}), 2-\mathrm{h}(\bigcirc)$, and 3-h ( $\boldsymbol{\square})$ retention, with $4-\mathrm{h}$ retention of more than $10 \%$ as the standard for delayed emptying. AUC values were $0.75,0.93$, and 0.97 at 1,2 , and $3 \mathrm{~h}$, respectively. FPF $=$ false-positive fraction; TPF $=$ true-positive fraction.

between the 3- and 4-h observation points. Thus, we would not recommend limiting the study to $3 \mathrm{~h}$.

Another limitation of the Tougas protocol is the lack of data defining rapid gastric emptying. Rapid emptying is not rare, having been reported to occur in $10 \%-40 \%$ of patients referred for suspected delayed gastric emptying (15-17). Symptoms are often indistinguishable from those of delayed emptying. Table 2 displays the results of patients with the most rapid emptying in this study. Although these results may suggest rapid emptying, they are not diagnostic, because there are no normative data. Normative data are sorely needed.

This simplified protocol can be modified by piggybacking other protocols-for example, liquid emptying or gastric accommodation - to answer a specific clinical or investigational question. We imaged every $10 \mathrm{~min}$ during the first hour to investigate the lag phase. Limited published data suggest that prolongation of the lag phase is the cause of delayed gastric emptying $(18,19)$ and that improvement in emptying with prokinetic therapy is due to shortening of the lag phase $(20,21)$. However, other published data have indicated no relationship between a prolonged lag phase and delayed emptying $(4,22)$. In our investigation, the lag phase was not predictive of delayed emptying.

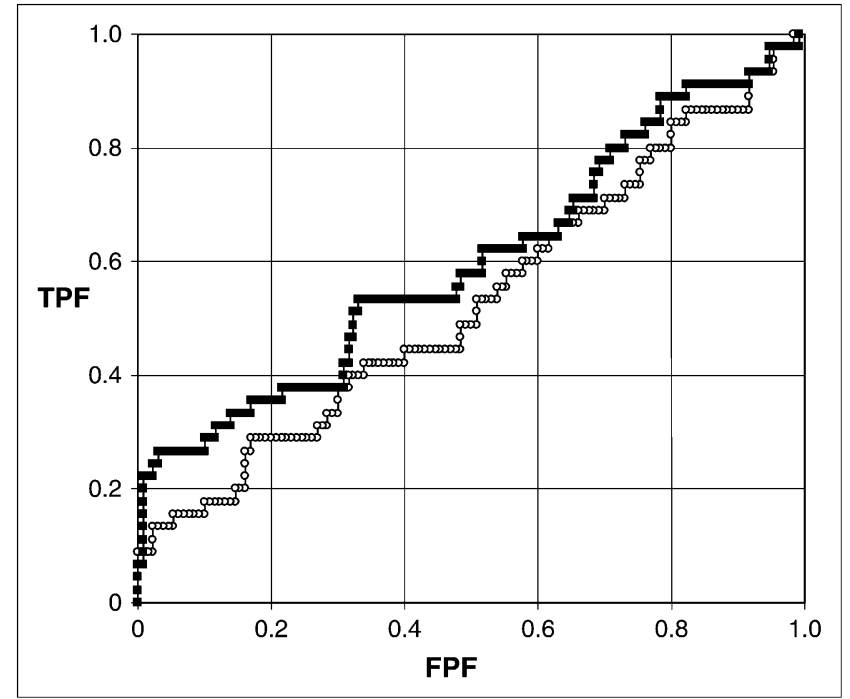

FIGURE 2. ROC curves for lag defined as first appearance of bowel activity $(\bigcirc)$, and lag defined as $5 \%$ emptying from peak activity ( $\square$ ). FPF $=$ false-positive fraction; TPF $=$ true-positive fraction.

It is uncertain how best to define abnormal emptying. For example, is a study abnormal if emptying is delayed at $4 \mathrm{~h}$, even though normal at $2 \mathrm{~h}$ ? Is a study abnormal if emptying is delayed at $2 \mathrm{~h}$ but normal at $4 \mathrm{~h}$ ? One study, measuring emptying at 2,3 , and $4 \mathrm{~h}$, showed that the number of abnormal studies increased if one considered emptying to be abnormal if delayed at any of these time points (2). Our data indicated the same. However, the clinical significance of these criteria is uncertain and requires further investigation.

\section{CONCLUSION}

To our knowledge, this investigation was the first clinical study using the simplified and standardized protocol of Tougas et al. on a large population of referred patients. We confirmed the preliminary data, reported from smaller patient groups using different protocols, meals, and reference values, that a 4-h study detects more patients with abnormal gastric emptying than does a 2-h study. By modifying the standardized protocol for research, we found that the lag phase is not predictive of delayed emptying.

TABLE 4

Threshold Values for Optimal Accuracy, with Associated Values for Sensitivity, Specificity, and Predictive Values

\begin{tabular}{lccccc}
\hline Gastric retention & Sensitivity & Specificity & Positive predictive value & Negative predictive value & Accuracy \\
\hline$>91 \%$ at $1 \mathrm{~h}$ & 29 & 97 & 76 & 79 & 79 \\
$>52 \%$ at $2 \mathrm{~h}$ & 80 & 89 & 71 & 93 & 87 \\
$>30 \%$ at $3 \mathrm{~h}$ & 82 & 95 & 84 & 94
\end{tabular}

Data are percentages. 


\section{REFERENCES}

1. Tougas G, Eaker EY, Abell TL, et al. Assessment of gastric emptying using a low fat meal: establishment of international control values. Am J Gastroenterol. 2000;95:1456-1462.

2. Guo J-P, Maurer AH, Fisher RS, Parkman HP. Extending gastric emptying scintigraphy from 2 to 4 hours detects more patients with gastroparesis. Dig Dis Sci. 2001;46:24-29.

3. Thomforde GM, Camilleri M, Phillips SF, Forstrom LA. Evaluation of an inexpensive screening scintigraphic test of gastric emptying. J Nucl Med. 1995;36:93-96.

4. Efron B, Tibshirani RJ. An Introduction to the Bootstrap. New York, NY: Chapman and Hall; 1993.

5. Ziessman HA, Atkins FB, Vemulakonda US, et al. Lag phase quantification for solid gastric empty studies. J Nucl Med. 1996;37:1639-1643.

6. Griffith GH, Owen GM, Kirkman S, Shields R. Measurement of the rate of gastric emptying using chromium-51. Lancet. 1966;1:1244-1245.

7. Christian PE, Datz FL, Moore JG. Confirmation of short solid-food lag phase by continuous monitoring of gastric emptying. J Nucl Med. 1991;32:1349-1352.

8. Elashoff JD, Reedy TJ, Meyer JH. Analysis of gastric emptying data. Gastroenterology. 1982;83:1306-1312.

9. Siegel JA, Urbaine JL, Adler LP, et al. Biphasic nature of gastric emptying. Gut. 1988;29:85-89.

10. Urbain JL, Vekemans MC, Parkman H, et al. Dynamic antral scintigraphy to characterize gastric antral motility in functional dyspepsia. J Nucl Med. 1995; 36:1579-1586.

11. Christian PE, Datz Fl, Sorenson JA, Taylor A. Technical factors in gastric emptying studies. J Nucl Med. 1983;24:264-267.
12. Kroop HS, Long WB, Alavi A, Hansell JR. Effect of water and fat on gastric emptying of solid meals. Gastroenterology. 1979;77:997-1000.

13. Ziessman HA, Fahey FH, Atkins FB, Tall J. Standardization and quantification of radionuclide solid gastric emptying studies. J Nucl Med. 2004;45:760-764.

14. Camilleri M, Zinsmeister AR, Greydanus MP, et al. Towards a less costly but accurate test of gastric emptying and small bowel transit. Dig Dis Sci. 1991;36: 609-615.

15. Lipp RW, Schnedl WJ, Hammer HF, et al. Evidence of accelerated gastric emptying in longstanding diabetic patients after ingestion of a semisolid meal. J Nucl Med. 1997;38:814-818.

16. Ziessman HA. Fahey FH, Collen MJ. Biphasic solid and liquid gastric emptying in normal controls and diabetics using continuous acquisition in LAO view. Dig Dis Sci. 1992;37:744-750.

17. Nowak TV, Johnson CP, Kabfleisch JH, et al. Highly variable gastric emptying in patients with insulin dependent diabetes mellitus. Gut. 1995;37:23-29.

18. Loo FD, Palomer DW, Soergel GH, et al. Gastric emptying patients with diabetes mellitus. Gastroenterology. 1984;86:485-494.

19. Horowitz M, Collins PJ, Cook DJ, et al. Abnormalities of gastric emptying in obese patients. Int J Obes. 1983;7:415-421.

20. Horowitz M, Harding PE, Chatterton BE, et al. Acute and chronic effects of domperidone on gastric emptying in diabetic autonomic neuropathy. Dig Dis Sci. 1985;30:1-9.

21. Urbain JL, Vantrappen G, Janssens J, et al. Intravenous erythromycin dramatically accelerates gastric emptying in gastroparesis diabeticorum and normals and abolishes the emptying discrimination between solids and liquids. $\mathrm{J} \mathrm{Nucl}$ Med. 1990;31:1490-1493.

22. Wright RA, Krinsky S, Fleeman C, et al. Gastric emptying and obesity. Gastroenterology. 1983;84:747-751. 